\title{
Novel Framework for Analysing the International Business Law: A Theory of Business Perspective
}

Althiabi Saad Saeed

Department of Law, College of Law and Judicial Studies, University of Jeddah; ssalthiabi@pnu.edu.sa

\begin{abstract}
Objectives: The main aim of this framework is to analyse the evolution of theories in the international business law and its implementation in worldwide for past decades. In this paper, an extensive review is done in order to bring the previous works which has been done in the international business law in terms of the application in business perspective. Method/Statistical Analysis: Various theories which are used earlier where analysed in detail. From the review, its noted that, over the past years, in the international business law has subjected to various improvements with new methodologies and models in based on the equalization of price, absolute and comparative type of advantages, model based on gravity etc. where analysed in detail. Findings: Various factors for improving the theories present in the field of international business law are discussed. This study incorporates the financial sections of the international business law with its impact on economic crisis. Application/Improvements: Future research can be an analysis of more factors which influence the business law in detail.
\end{abstract}

Keywords: Company, Customers, Factors of Business, Income, International Business Law, PESTEL Analysis

\section{Introduction}

A business is considered as a process of performing any tasks with the motivation profit. Its main aim is to make a sustainable organizational business. In order to attain this sustainability, these firms follow a procedure to find all the available the opportunities and convert all of them for reaching the sustainable position. The possible chances making a firm more sustainable are reduction in cost, difference in the product, products with high quality, expansion of the business to an international level, addition of value to products etc. Hence, various firms of the business which is initially established in one particular country extended the business process to another country as internationally and hence they became business firms of worldwide. This process of extension changed the firms towards a multinational based business companies which has more number of branches.

The international business is being a situation, where all the participant countries or firms are going to get benefits therefore, the method of performing a business by enhancing the harmony of it and by reducing the obstacles present in it begin to be the foremost agenda of the administration of various nations. In order to bear the globalised business, these authorities has proposed various strategies and created many policies to boost the focus on international business by all the available ways. Hence, the international business organisations which have the $g$ attaining more payback by elaborating the business to various other nations through the international business market for their commodity/goods or by the way of international based production got major business and stake holders internationally and therefore they become less priced producers.

Any firm which has plans to go for international investment for production or marketing studies the various factors which influence the business in nationally and internationally. This analysis comprises of responsible conclusions established from the available resources. These analysis forecast mainly on the upcoming chances of the business. Certainly, these factors are considered as important nowadays as a base for the upcoming business ${ }^{1-5}$. 
Various factors which effects in the international business are as follows:

- Political Factor

- Economic Factor

- Socio-cultural Factor

- Technological Factor

- Environmental factor

- Legal Factor

\section{Objectives of the Proposed Framework}

In this study, we have discussed various business analyses which influence the business system, the strategy used by many international firms and the factors which are influencing their business with the following intention:

- To have an insight into major factors which influences the business of a firm internationally?

- To know various substructures which are used to examine the business resolution of an international organization based on its internal and external environments. This includes studying its operational environment, business environment, and corporate environment.

- To analyse the foremost, methods which are recognised based on the analysis framework, many factors which are applied in the analysis, issues which is most required and applications of the outcomes obtained from the analysis which is linked to the upcoming investments and continuing the existing business in different countries.

- To apply a predefined methodology in order to find the advantage, disadvantage, chances, and problems of an organization in terms of the doing the business internationally.

- To use a predefined framework to find the benefits, merits, limitations, and the drawbacks of the prior done analysis, factors etc.

\section{General Theories of International Business Law}

International business law is the collection of treaties, conventions and agreements between nations, which have more or less the force of law ${ }^{6}$. They are usually multilateral among many nations. International business is the process of buying and/or sells products by a company or firm across the boundaries of two or more countries, even if ruling council is present in one of the nations. It has become large in size with a majority of impact on political based, economic based and social based factors. It has different types of business principles and from the idea of various business tasks done internationally. Foreign business is the method performing trading as domestic operations with a foreign country. Registered intellectual properties and unique right called as patents of inventions are protected by international law proposed by the world intellectual property organization. In order to void the Infringements done by patent owners, various laws are also proposed to regulate the conduct of the business. These laws cover such matters as standards of products, packaging, promotion etc.

\section{Analysis on the Factors of Business Law}

An analysis called PESTEL $\underline{7,8}$ (Political, Economic, Social, Technological, Environmental and Legal) shown in Figure 1 is a substructure applied to find the business architecture. This PESTEL analysis finds out the opportunities and challenges in international business investment ${ }^{2}$. Main elements of the PESTEL analysis are as follows.

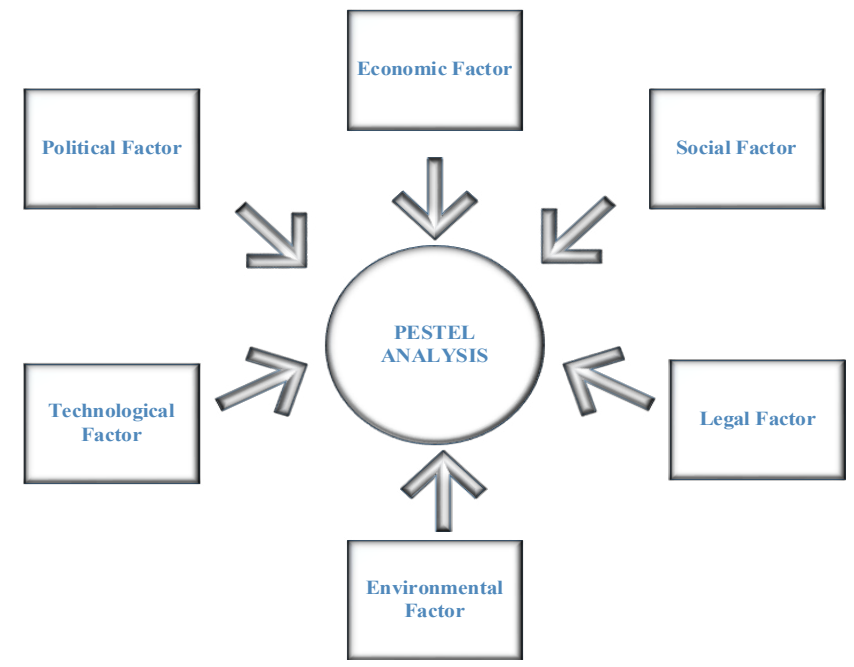

Figure 1. PESTEL Analysis.

\subsection{Political Factor}

The political environment in which major resolutions are taken by a firm of the international business based on the home country political environment, the domestic country political environment, and the global political environment. 
These factors given above may have influences directly or an indirectly on the resolutions of the international business and also favourable applications firm. While making a decision on the international investment, the business managers would prefer a political environment that was fully supportive for business.

\subsubsection{Political Factor of the Home Country}

Based on the international business law, the politics of domestic country cannot affect the company's activities and decisions done internationally. But in reality, due to changes in political conditions and changes in governing political parties, the Country policy and State government policies are changing. In another example, the domestic firms that continue to invest and manufacture abroad ignoring their domestic country are often accused for not contributing to solve domestic unemployment problems and hence may get political pressure from the domestic country. Hence, all the resolutions taken by an international business company may be denounced by the domestic country.

\subsection{The Economical Factor}

The economical factor is the major threshold for the policies taken by an international business firm. It is also one of the parameter for fame of the trade which is dome internationally. This factor covers both domestic or national and international or global. There exist various parameters for evaluating the economic environment in which majority of the firms operating internationally. These indicators are population, Income of per capita, Distribution of income, and the economical type of both domestic and international countries.

\subsubsection{Population}

Size of the market is a basic parameter for customers and their ability of purchase. In general, the larger the population, the better is the market. Although it is rational to suggest that there is no connection with the size of customers and their buying capacity, and the potential of sales. It is it is based on an assumption that the customers are primary indicator of the size of any market. Many goods such as food, drugs, electronics, and other basic but essential products get greater demand if the population is higher. Customers, their population and the distribution throughout geographically can also be considered.
The pattern of shopping in cities varies considerably compared to villages. Various parameters such as age, education should also be considered while taking the decisions on international business.

\subsubsection{Per Capita Income}

Distribution of income is also a major factor while assessing the economic environment. Income of per capita measures the performance of an economy with respect to the population. With respect to the income of per capita, the nation's economy can be differentiated as four types. They are the economies of high income, upper middle, lower middle and low. However, it is misleading to rely completely based on the income of per capita in evaluating a country's marketing potential and ability in supporting international firms.

\subsubsection{Distribution of Income}

International firms must be considered as income distribution among the people instead of depending on the income of per capita only. This is because, in case of some goods namely luxury items which is not a basic need gets less attraction from major customers. Instead, very less peoples gets attracted and purchases these items. In some countries with poor economy, where wealth is based on very less population, the demand is comparable to the pattern of demand in rich countries.

\subsubsection{Economical Type}

In terms of investment, the condition economy of a country and the people's nature of spending decisions also impact the company's success. If the nature of the people in a country more spending type out of the earned money eitherby saving for future requirements, then the chance of success will be more for the investors who are investing internationally. Hence, based on the peoples nature in expenditure and the earning ability in different types of economies like, High, Upper-middle, Lower-middle, and in Low economies attract potential investments from internationally.

\subsection{Socio-Cultural Factor}

Factor based on the socio-culture comprises of set of variables, assumptions, protocols, and organizations taken care by certain set of peoples within the society. When 
the concept of globalisation improved, the reduction of socio-culture factor is carried out which leads to a drastic change in the views of customers, their living style and the performance may be awful for a company doing multinational business $\frac{10,11}{}$. This factor downgrades all the marketing characteristics. It downgrades the view of consumer regarding the products, its availability, cost of price etc. For example, it affects the name of product, cost of the product, offers available for the product etc.

\subsection{Technological Environment}

Transform of technology have become the important factors in the international business decisions. The technology is changing at a greater speed due to continuous efforts of the research and developments section in firm's majority of the countries. The impact of advancements in technology on international business and its resolutions had an important effect during the recent years ${ }^{12}$. Advancements in technology lead the most competitive advantage to the multinational firms in order to expand their business to many nations against the competition from local competitor firms.

\subsection{Environmental Factor}

Ecological factors, such as subsidizing the natural resources, climatic factors, physical features of an area, characteristics of locality, airport \& water-port facilities, etc., are all relevant to international business. The dissimilarity in the conditions of locations between firms. These factors impact the locality of some firms. Example, the firms which requires a particular resource should be available.

\subsection{Legal Factor}

Legal factor is important in any country for the process of investing internationally and to point out the activities of business. Each country has its own system of legal environment which displays its beliefs and values of cultural, socio and political factors etc. Multinational company's deals with the legal environment throughout the world while framing there solutions on international business. Three aspects of the legal environment factors laws in the home country, laws in the host country, and laws followed internationally.

\section{Conclusion and Future Enhancements}

In this study, the theories of international trade and international business law is analysed as a framework. It describes the advent and development of trade theories beginning from Mercantilist theory till gravity model. Various factors which influence the different theories of international trade based on the international business law and its applications is analysed. Factors such as the Political based, Economical based, Socio-cultural base, Technological based, Environmental based and the Legal based factors where discussed in detail. One of the important business frameworks called PESTEL is analysed and explained in depth. Since there is a drastic change in the world economy, the necessity to bring up new trade models is needed. These improvements can effect in the international business more precisely. Future direction for research has been outlined based on analysing these factors. Future research can be a focus on the effects of international business law and its applications in the economy. This analysis can determine the relationship between international business investments, its factors with the growth of the economy.

\section{References}

1. UNCTAD. Key statistics and trends in international trade. United Nations Publication. Geneva, Switzerland. 2015; p. 1-30.

2. Krugman P. Scale Economies, Product Differentiation, and the Pattern of Trade. The American Economic Review. 1980; 70:950-9.

3. Zidi A, Dhifallah SM. Trade Creation and Trade Diversion between Tunisia and EU: Analysis by Gravity Model. International Journal of Economics and Finance. 2013; 5(5):131-47. https://doi.org/10.5539/ijef.v5n5p131

4. Eichengreen B, Rhee Y, Tong H. China and the Exports of Other Asian Countries. Review of World Economics. 2007; 143(2):201-26. https://doi.org/10.1007/s10290-007-0105-0

5. Panda R, Sethi M, Chaudhuri S. Changing Paradigm in Trade Theories: A Review and Future Research Agenda. Indian Journal of Science and Technology. 2015; 9(46). https://doi.org/10.17485/ijst/2016/v9i46/107291

6. International trade statistics. World Trade Organization. 2015; p. 1-170. 
7. Issa $\mathrm{T}$, Chang V, Issa $\mathrm{T}$. Sustainable business strategies and PESTEL framework. GSTF International Journal on Computing. 2010; 1(1):73-80. https://doi.org/10.5176/20102283_1.1.13

8. Aguilar Francis J. Scanning the business environment. New York, Macmillan. 1967; p. 1-237.

9. Aithal PS. ABCD Analysis as Research Methodology in Company Case Studies. International Journal of Management, Technology, and Social Sciences. 2017; 2(2):40-54.

10. Terjesen S, Hessels J, Li D. Comparative international entrepreneurship: A review and research agenda.
Journal of Management. 2016; 42(1):299-44. https://doi. org/10.1177/0149206313486259

11. Welch LS, Luostarinen R. Internationalization: Evolution of a concept. Journal of General Management. 1988; 14(2): 34-55. https://doi.org/10.1177/030630708801400203

12. Aithal PS, Aithal S. A New Model for Commercialization of Nanotechnology Products and Services. International Journal of Computational Research and Development. 2016; 1(1):84-93. 